\title{
Vibrational spectroscopy studies on linear polyamines
}

\author{
M.P.M. Marques ${ }^{1}$ and L.A.E. Batista de Carvalho \\ Research Unit "Molecular Physical-Chemistry", University of Coimbra, 3000 Coimbra, Portugal
}

\begin{abstract}
Vibrational spectroscopy [both Raman and INS (inelastic neutron scattering)], coupled to quantum mechanical calculations, was used in order to perform a thorough structural analysis of linear polyamines and polynuclear polyamine metal chelates [e.g. with $\mathrm{Pt}(\mathrm{II})$ and $\mathrm{Pd}(\mathrm{II})$ ] with potential anticancer activity. The complementarity of the Raman and INS spectroscopies was exploited in order to gain a better knowledge of the conformational behaviour of these systems. Moreover, the conjugation of the experimental spectroscopic data to the theoretical results allows us to obtain valuable information on the structural preferences of this kind of system, which may lead to the establishment of SARs (structure-activity relationships) ruling their biological activity. Some of the most significant results obtained by the 'Molecular Physical-Chemistry' Research Group of the University of Coimbra (Portugal) are reviewed here.
\end{abstract}

\section{Introduction}

The activity of a biologically relevant compound does not rely solely on its chemical properties, but it is also dependent on its conformational preferences, which must be accurately determined if thorough understanding of the function and mechanisms through which this kind of system acts is to be obtained. Vibrational spectroscopy is an especially useful technique for achieving this goal, since it yields valuable structural evidence based on the analysis of the vibrational modes associated with each chemical group (oscillator) within the molecule.

Raman spectroscopy, in particular, has proved to be a reliable method for the characterization and conformational analysis of biologically active compounds, apart from allowing an accurate determination of the composition profile of solid samples, since it provides unique fingerprint spectra for each compound [1]. Actually, owing to its non-invasiveness, high sensitivity and good reproducibility, this technique, which does not need any special sample preparation, is becoming a valuable tool in the fields of biochemistry and medicinal chemistry. One of its major advantages for biochemical studies is the fact that water is virtually transparent to the Raman effect, which enables the collection of good quality spectra for rather diluted aqueous samples.

INS (inelastic neutron scattering), in turn, is a vibrational spectroscopy technique particularly suited for investigating highly hydrogenated systems [2]. In fact, since neutrons have a mass similar to that of the hydrogen atom, an inelastic collision between them involves a significant transfer of both momentum and energy, and the modes involving a hydrogen

Key words: biogenic polyamine, conformational analysis, linear diamine, polyamine complex theoretical calculation, vibrational spectroscopy.

Abbreviations used: DFT, density functional theory; INS, inelastic neutron scattering; LAM, longitudinal acoustic mode; MPT, mitochondrial permeability transition; SAR, structure-activity relationship; TAM, transverse acoustic mode.

${ }^{1}$ To whom correspondence should be addressed (email pmc@ci.uc.pt). displacement will thus dominate the spectrum (the scattering cross-section for hydrogen is 80 barns as opposed to approx. 5 barns for most other elements). Therefore INS allows the detection of vibrational modes not available to the conventional Raman and IR optical methods. In fact, since INS is not subject to the photon selection rules, all vibrations are active. This technique is thus complementary to Raman and IR: while INS yields a clear and intense vibrational pattern in the frequency range below approx. $600 \mathrm{~cm}^{-1}$, its spectral quality begins to deteriorate above approx. $1800 \mathrm{~cm}^{-1}$, where Raman spectroscopy becomes particularly useful, namely for the analysis of $\mathrm{XH} / \mathrm{XD}(\mathrm{X}=\mathrm{C}, \mathrm{N}, \mathrm{O})$ stretching modes.

Furthermore, Raman and INS band positions and intensities can be calculated through theoretical methods \{using dedicated programs such as Gaussian, revision B.04 (http:// www.gaussian.com) and aCLIMAX [4]\}, leading to an accurate simulation of the spectra. This enables us to link the spectroscopic features to molecular geometry and to achieve a thorough conformational analysis of the systems under investigation.

Biogenic polyamines, putrescine $\left[\mathrm{H}_{2} \mathrm{~N}\left(\mathrm{CH}_{2}\right)_{4} \mathrm{NH}_{2}\right]$, spermidine $\left[\mathrm{H}_{2} \mathrm{~N}\left(\mathrm{CH}_{2}\right)_{3} \mathrm{NH}\left(\mathrm{CH}_{2}\right)_{4} \mathrm{NH}_{2}\right]$ and spermine $\left[\mathrm{H}_{2} \mathrm{~N}\left(\mathrm{CH}_{2}\right)_{3} \mathrm{NH}\left(\mathrm{CH}_{2}\right)_{4} \mathrm{NH}\left(\mathrm{CH}_{2}\right)_{3} \mathrm{NH}_{2}\right]$, are ubiquitous in cells of higher organisms, and result from the decarboxylation of basic amino acids. Under physiological conditions, these linear amines are totally protonated and behave as natural polycations, capable of interacting with both DNA and RNA [5]. They are known to be implicated in a bewildering number of cellular functions [6-11], being essential for eukaryotic cell growth and differentiation, as well as for maintaining the native structure of several biological macromolecules while affecting the activity of others [6,12], through tightly regulated concentration-dependent processes. Because of the absolute polyamine requirement for cell growth, interference with polyamine biosynthesis can be a rather promising 
therapeutic approach against neoplastic diseases. The highly sensitive SARs (structure-activity relationships) that underlie and control this vital biological role of polyamines/polyamine function are very poorly known, which calls for a thorough knowledge of their structural behaviour.

Since Rosenberg's discovery of an unexpected inhibition of cell division in the presence of cisplatin $\left[\right.$ cis- $\mathrm{Pt}\left(\mathrm{Cl}_{2}\left(\mathrm{NH}_{3}\right)_{2}\right]$, in the late 1960s [13], the square-planar platinum(II) and palladium(II) complexes have become of increasing importance in the design of new anticancer agents $[14,15]$. The multinuclear $\mathrm{Pt}(\mathrm{II})$ chelates comprising two or three cisplatinlike moieties $\left[\mathrm{Pt}\left(\mathrm{NH}_{3}\right)_{2} \mathrm{Cl}\right.$ or $\left.\mathrm{Pt}\left(\mathrm{NH}_{3}\right) \mathrm{Cl}_{2}\right]$ and variablelength polyamines as bridging linkers, in particular, have lately been the target of intense research due to the recognized enhancement of their cytotoxic effect in comparison with the currently used drugs [16-21]. In fact, many of these complexes were found to yield DNA adducts not available to the conventional alkylating agents, through long-distance intra- and inter-strand cross-links [22,23], leading to different types of drug-induced DNA lesions. Since DNA attack by this type of chelate (and consequent cytotoxicity) depends strongly on their chemical nature and structural preferences, a thorough conformational study of these potential antineoplastic compounds, at the molecular level, is essential for a rational design of second- and third-generation anticancer drugs, coupling an improved toxicological profile to a lower toxicity.

The present review reports the use of vibrational spectroscopy, coupled to theoretical calculations [at the DFT (density functional theory) level], for the conformational study of polyamines and their $\mathrm{Pt}(\mathrm{II})$ and $\mathrm{Pd}(\mathrm{II})$ co-ordination compounds. The biogenic polyamines spermidine and spermine were investigated, as well as the homologous series of $\alpha, \omega$-diamines $\mathrm{H}_{2} \mathrm{~N}\left(\mathrm{CH}_{2}\right)_{n} \mathrm{NH}_{2}(n=2-10, n=12)$ (which includes putrescine, $n=4)$. Several polynuclear spermidine and spermine $\mathrm{Pt}(\mathrm{II})$ and $\mathrm{Pd}(\mathrm{II})$ chelates with potential anticancer activity were studied, differing in the metal-co-ordination pattern and in the number and geometry of their leaving groups. The Raman and INS complementarity was exploited in order to gain a better knowledge of the conformational behaviour of these systems. In particular, the low-frequency TAM and LAM (transverse and longitudinal acoustic modes respectively) characteristics of the linear aliphatic amines studied were detected and assigned.

The results obtained from these studies may hopefully contribute to a better understanding of the biochemical function of polyamines and polyamine-based systems at a molecular level, through the determination of the SARs ruling this activity.

\section{Results and discussion}

\section{Aliphatic linear polyamines}

The homologous series of the linear $\alpha, \omega$-diamines $\left[\mathrm{H}_{2} \mathrm{~N}\left(\mathrm{CH}_{2}\right)_{n} \mathrm{NH}_{2}\right](n=2-10, n=12)$ and the tri- and tetramines spermidine and spermine (Figures $1 \mathrm{~A}-1 \mathrm{C}$ ) were stud- ied in order to achieve a thorough knowledge of their structural preferences, both for their unprotonated and Nprotonated forms [24-33]. Several theoretical molecular models were proposed for an accurate representation of these linear polyamines, yielding the best possible agreement with the experimental data (both vibrational spectroscopy results and reported X-ray structures).

These kinds of molecules are characterized by a high conformational freedom, and by an interdependence of the particular effects due to the nitrogens' electronegativity and electron lone-pairs. These lead to the formation of intraand inter-molecular hydrogen bonds (e.g. $\mathrm{R}-\mathrm{HN}-\mathrm{H} \cdots \mathrm{NH}_{2}-$ $\mathrm{R})$, which determine the solid-state conformational behaviour of the linear amines and may give rise to either infinite chain polymeric forms or dimeric species \{namely for $\mathrm{H}_{2} \mathrm{~N}\left(\mathrm{CH}_{2}\right)_{2} \mathrm{NH}_{2}$ [28]\}, in accordance with the theoretical predictions [32]. Although the intramolecular $(\mathrm{C}) \mathrm{H}^{\cdots}: \mathrm{N}$ interactions were found to be of moderate strength [calculated (C) $\mathrm{H}^{\cdots}: \mathrm{N}$ distances approx. 250 to $280 \mathrm{pm}$ ], the $(\mathrm{N}) \mathrm{H}^{\cdots} \cdot \mathrm{N}$ close contacts were verified to be rather strong [calculated (N)H' $\mathrm{H}^{\cdots}: \mathrm{N}$ distances approx. 200 to $210 \mathrm{pm}$ ]. Actually, these hydrogen-type bonds were clearly evident by the shift to low frequencies detected for the Raman $\mathrm{NH}_{2}$ stretching bands when going from the pure liquid to the condensed phase [24].

Since biogenic amines are physiological polycations, the effect of protonation on their conformational behaviour was investigated by analysing the corresponding vibrational pattern as a function of $\mathrm{pH}$ (Figure $2 \mathrm{~A}$ ). In the totally $\mathrm{N}$ protonated state, only the all-trans conformation was found to occur, thus hindering the formation of intramolecular $(\mathrm{N}) \mathrm{H}^{\cdots}: \mathrm{N}$ or $(\mathrm{C}) \mathrm{H} \cdots: \mathrm{N}$ hydrogen bonds. Under these conditions, the linear polyamines behave as saturated alkanes, for which the all-trans geometry has long been recognized to be energetically favoured over the gauche ones [34].

Deuteration of the samples allowed an unequivocal assignment of the $\mathrm{NH}_{2}$ oscillators. In fact, this led to the anticipated shifts to lower frequencies of the $\mathrm{NH}_{2} / \mathrm{ND}_{2}$ stretching modes in both INS and Raman (as well as to the loss of some INS intensity), as a consequence of the variations in both mass (frequencies) and scattering cross-section (INS intensities) (Figure 2B). The analysis of the $\mathrm{C}-\mathrm{H}$ stretching region of the Raman spectra allowed us to conclude that $\mathrm{N}$-deuteration does not significantly affect the intermolecular forces and hydrocarbon flexibility of the linear polyamines, as opposed to $\mathrm{N}$-protonation, which leads to a marked increase in the rigidity of these systems [29].

Furthermore, the complementary use of the Raman and INS techniques allowed the observation and assignment of the whole set of transverse and longitudinal acoustic vibrational modes (TAMs and LAMs) for these polyamines (Figure 3 ), both for their undeuterated and $\mathrm{N}$-deuterated forms $[28,33]$.

\section{Agmatine}

Agmatine [4-(aminobutyl)guanidine] (Figure 1D), produced by decarboxylation of L-arginine, displays a wide range of physiological functions [35], from neuromodulator [36], 
Figure 1| Lowest-energy calculated structures for some of the polyamines and polyamine complexes studied in the present work (A) $\alpha, \omega$-Diamines $\mathrm{H}_{3} \mathrm{~N}\left(\mathrm{CH}_{2}\right)_{n} \mathrm{NH}_{3}(n=2-10, n=12)$; (B) spermidine; $(\mathbf{C})$ spermine; $(\mathbf{D})$ agmatine; $(\mathbf{E})\left(\mathrm{PtCl}_{2}\right)_{3}(\mathrm{Spd})_{2}$ (Spd = spermidine). The amines are represented in their $\mathrm{N}$-protonated, physiological forms.

A

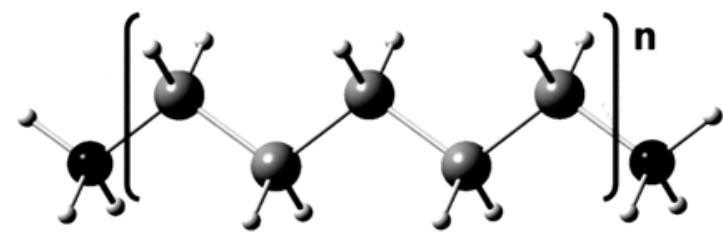

B

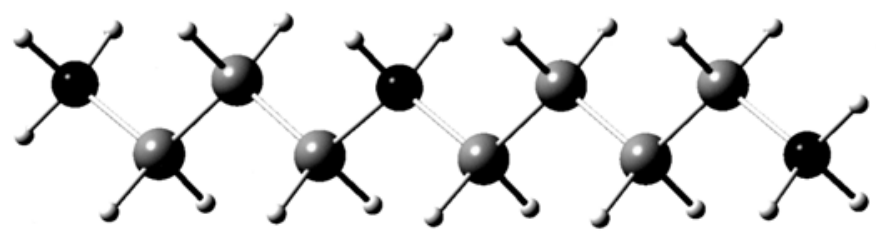

C

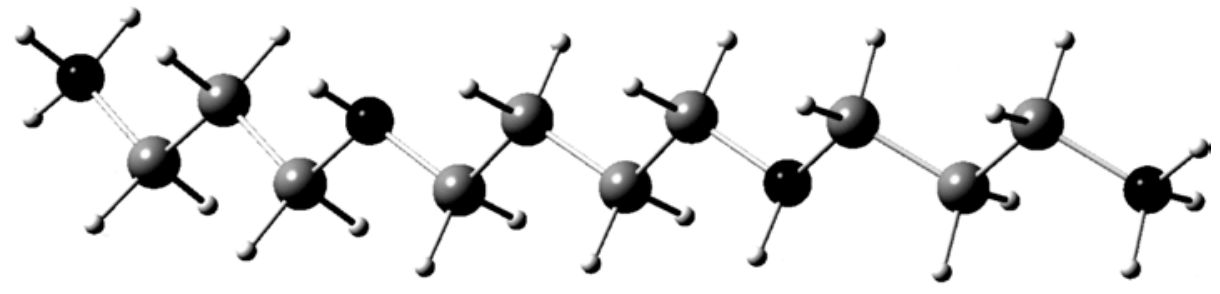

D

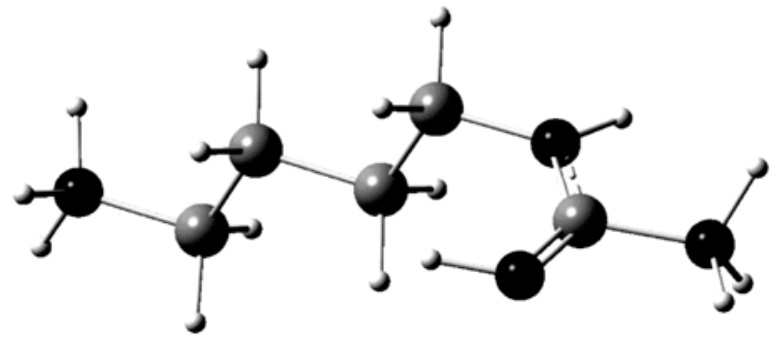

$\mathbf{E}$

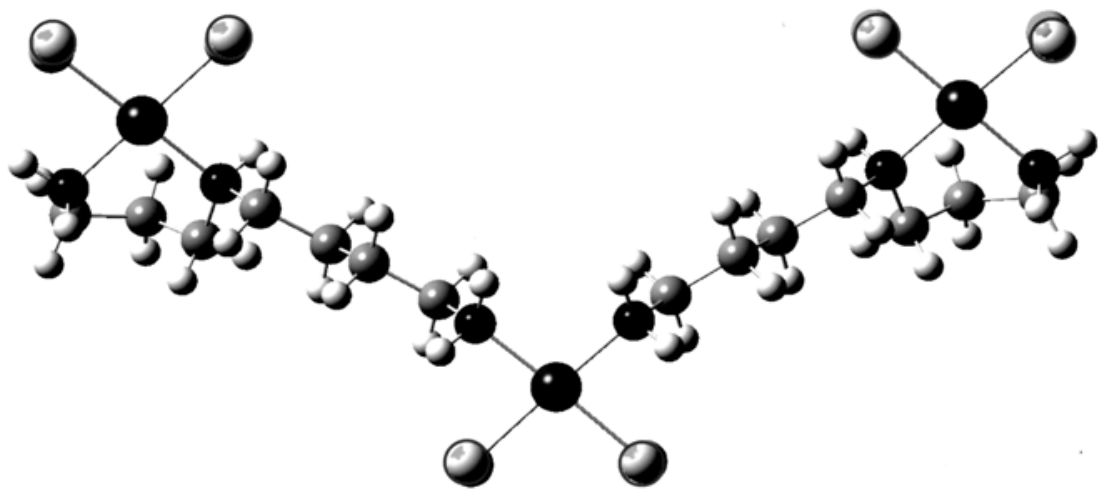

$\mathrm{C} \bigcirc \mathrm{N}, \mathrm{H}$

Cl 
Figure 2 | Experimental Raman spectra (solid state, at room temperature)

(A) Putrescine, in the neutral (I) and cationic (N-protonated) (II) forms; (B) spermidine, in the undeuterated (I) and $\mathrm{N}$-deuterated (II) forms. The most stable calculated geometries for neutral and cationic putrescine are also represented.
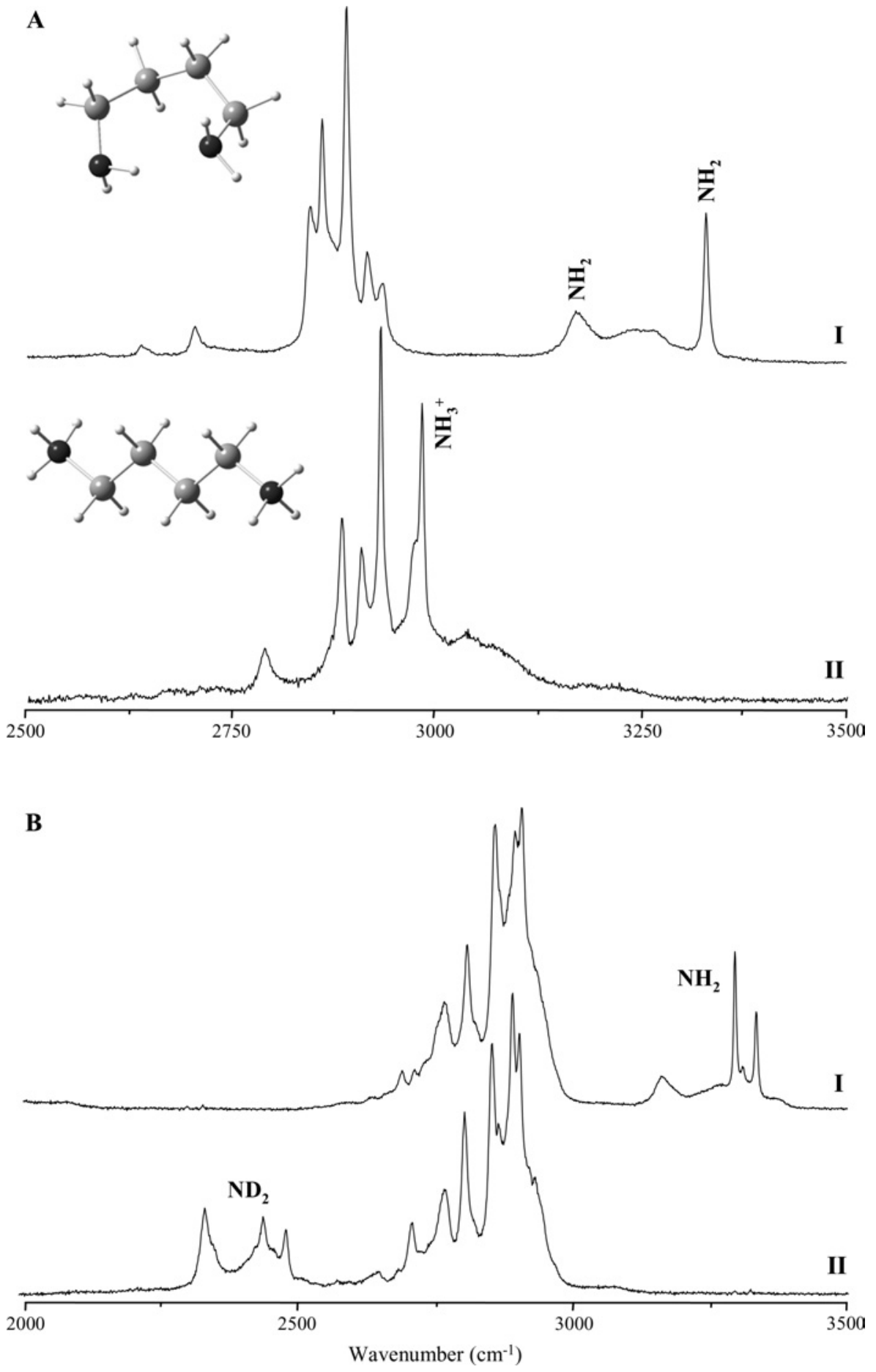

to stimulator of insulin release [37] or even tumoursuppressor agent [38-41]. As for other biogenic polyamines, the activity of agmatine as a transportable cation and biological effector is strongly dependent on its structural preferences, which must be determined as an essential step for understanding its diverse biochemical functions, namely its specific transport mechanism and its effect on the MPT (mitochondrial permeability transition) potential.

The conformational study developed in our laboratory aimed at a better knowledge of the role of agmatine in biological systems, namely in rat liver mitochondria [42]. Raman spectroscopy combined with DFT calculations was used [43], 
Figure 3 Experimental INS and Raman spectra (solid state) for $\mathrm{H}_{2} \mathrm{~N}\left(\mathrm{CH}_{2}\right)_{10} \mathrm{NH}_{2}(A)$ and $\mathrm{H}_{2} \mathrm{~N}\left(\mathrm{CH}_{2}\right)_{6} \mathrm{NH}_{2}(B)$ The numbers refer to the TAM (A) and LAM vibrations $(\mathbf{B})$.

\section{A}

$\mathrm{H}_{2} \mathrm{~N}\left(\mathrm{CH}_{2}\right)_{10} \mathrm{NH}_{2}$
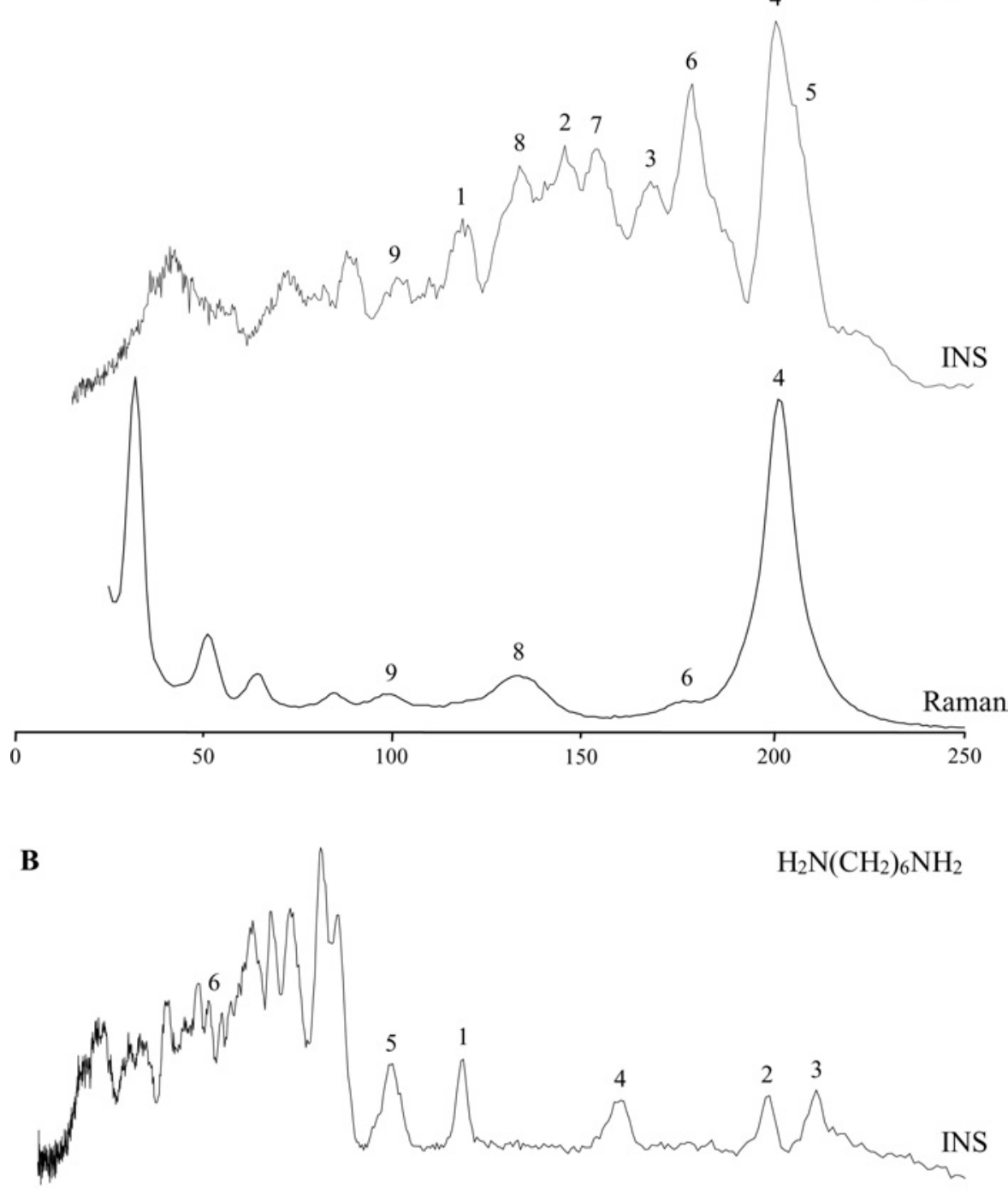

$\mathrm{H}_{2} \mathrm{~N}\left(\mathrm{CH}_{2}\right)_{6} \mathrm{NH}_{2}$

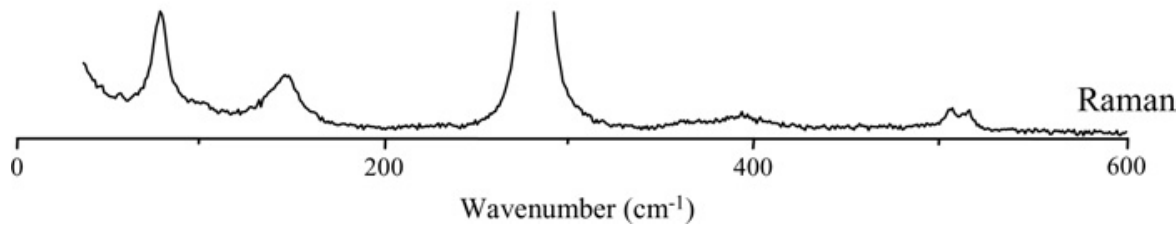

both for the solid samples and for aqueous solutions in distinct protonation states. A complete assignment of the corresponding Raman spectra was carried out, in the light of the theoretical results and the experimental data obtained for similar polyamines.

An accurate structural characterization of the most stable geometries of agmatine in solution, under different $\mathrm{pH}$ conditions, was achieved: at physiological $\mathrm{pH}$, the diprotonated (dipositive) species (Figure 1D); at moderate alkaline $\mathrm{pH}$ (up to approx. 9.0), the monoprotonated (monopositive) form; and in strong alkaline medium, the totally unprotonated (neutral) molecule. Moreover, the very good agreement between the experimental and calculated vibrational data obtained for agmatine, coupled to the clear detection of the expected changes due to $\mathrm{N}$-protonation in the Raman spectra, enabled an easy and unequivocal determination of agmatine's protonation states by analysis of the corresponding Raman pattern in aqueous solution.

These results allowed us to identify the agmatine structures prone to interact with the mitochondrial site responsible for its transport and for protection against MPT induction. These were found to be the dicationic species, displaying a lower negative charge in the protonated aliphatic $\mathrm{N}$-terminal relative to the monopositive or neutral forms of the molecule. 
Most probably, this is also the conformation to be found in the biological fluids during agmatine absorption from the diet, as well as in the cytosol, in mammalian cells. These studies are essential for the development of new agmatinebased therapeutic strategies (e.g. against drug addiction, painkilling or tumour suppressing).

\section{Polynuclear polyamine Pt(II) and Pd(II) chelates}

Several new polynuclear $\mathrm{Pt}(\mathrm{II})$ and $\mathrm{Pd}(\mathrm{II})$ polyamine chelates were synthesized in our laboratory (Figure 1E) and their conformational preferences determined by vibrational spectroscopy (Raman and INS) coupled to quantum mechanical calculations [44]. In order to better understand the influence of the structural features on the antineoplastic properties of these systems, they were designed to differ in one of the following parameters: type and number of metal ion(s); coordination pattern and chemical environment of the metal(s); distance between the metal centres; structural properties of the ligand(s); total electric charge.

The INS spectra were simulated from the normal mode eigenvectors yielded by DFT calculations [using the relativistic ECP (effective core potential) approximation for the representation of the metal]. Particular attention was paid to characteristic spectral regions, namely the ones comprising (i) the $\mathrm{NH}_{3}$ torsions, (ii) the $\mathrm{N}-\mathrm{M}-\mathrm{Cl}$ and $\mathrm{N}-\mathrm{M}-\mathrm{N}$ deformations $(\mathrm{M}=\mathrm{Pt}, \mathrm{Pd})$, and (iii) the vibrational feature characteristic of the polyamine ligands. Apart from the $\mathrm{CH}$ and $\mathrm{NH}$ torsion and deformation modes, all the oscillators involving the metal (e.g. $\mathrm{M}-\mathrm{N}$ and $\mathrm{M}-\mathrm{Cl}$ ), both stretching and bending, were observed and assigned. Furthermore, the study allowed us to compare the low lying N-M-Cl and N-M$\mathrm{N}$ deformations for both the $\mathrm{Pd}(\mathrm{II})$ and $\mathrm{Pt}(\mathrm{II})$ homologous chelates and thus determine the effect of the metal on these particular vibrational bands, which can be considered as a fingerprint of this kind of complex.

The knowledge gathered by this type of study, together with concurrent biochemical assays for the quantification of the in vitro anti-proliferative and/or cytotoxic effects of the polyamine complexes towards distinct human cancer cell lines [45-47], may contribute to the determination of the highly sensitive SARs that underlie and control the biological function of polyamines and their metal chelates in eukaryotic organisms. This will hopefully help us to expose the molecular basis of toxicity, aiming at the design of new and more efficient anticancer agents for future clinical use.

We acknowledge financial support from FCT (Portugal): projects POCTI/33199/QUI/2000 and POCTI/47256/QUI/2002 (co-financed by the European Community fund FEDER); European Unit EU/IHP Programme for ISIS Neutrons; and ESF: COST Action 922.

\section{References}

1 Carey, P.R. (1999) J. Biol. Chem. 274, 26625-26628

2 Mitchell, P.C.H., Parker, S.F., Ramirez-Cuesta, A.J. and Tomkinson, J. (2005) in Series on Neutron Techniques and Applications, Vol. 3: Vibrational Spectroscopy with Neutrons (Finney, J.L. and Worcester, D.L., eds.), World Scientific, Singapore
3 Reference deleted

4 Ramirez-Cuesta, A.J. (2004) Comput. Phys. Commun. 157, 226-238

5 Antony, T., Thomas, T., Shirahata, A. and Thomas, T.J. (1999) Biochemistry 38, 10775-10784

6 Tabor, C.W. and Tabor, H. (1984) Annu. Rev. Biochem. 53, 749-790

7 Auvinen, M., Passinen, A., Anderson, L.C. and Holtta, E. (1992) Nature $\mathbf{3 6 0}, 355-358$

8 O'Brien, T.G., Megosh, L.C., Gilliard, G. and Soler, A.P. (1997) Cancer Res. 57, 2630-2637

9 Xie, X., Gillies, R.J. and Gerner, E.W. (1997) J. Biol. Chem. 272 20484-20489

10 Vassileva, V. and Ignatov, G. (1999) Bulg. J. Plant Physiol. 25, 49-57

11 Guo, D. and Lu, Z. (2000) J. Gen. Physiol. 115, 783-797

12 Medina, M.A., Urdiales, J.L., Rodriguez-Caso, C., Ramírez, F.J. and Sánchez-Jiménez, F. (2003) Crit. Rev. Biochem. Mol. Biol. 38, 23-59

13 Rosenberg, B., Van Camp, L., Trosko, J.E. and Mansour, V.H. (1969) Nature 222, 385-386

14 Wong, E. and Giandomenico, C.M. (1999) Chem. Rev. 99, 2451-2466

15 Reedijk, J. (1999) Chem. Rev. 99, 2499-2510

16 Amo-Ochoa, P., González, V.M., Pérez, J.M., Masaguer, J.R., Alonso, C. and Navarro-Ranninger, C. (1996) J. Inorg. Biochem. 64, 287-299

17 Fogel-Petrovic, M., Kramer, D.L., Vujcic, S., Miller, J., Mcmanis, J.S., Bergeron, R.J. and Porter, C.W. (1997) Mol. Pharmacol. 52, 69-74

18 Servidei, T., Ferlini, C., Riccardi, A., Meco, D., Scambi, G., Segni, G., Manzotti, C. and Riccardi, R. (2001) Eur. J. Cancer 37, 930-938

19 Cox, J.W., Berners-Price, S.J., Davies, M.S., Qu, Y. and Farrell, N. (2001) J. Am. Chem. Soc. 123, 1316-1326

20 McGregor, T.D., Hegmans, A., Kaspárková, J., Neplechová, K., Nováková, 0., Penazová, H., Vrána, 0., Brabec, V. and Farrell, N. (2002) J. Biol. Inorg. Chem. 7, 397-404

21 Qu, Y., Scarsdale, N.J., Tran, M.C. and Farrell, N. (2003) J. Biol. Inorg. Chem. 8, 19-28

22 Farrell, N., Appleton, T.G., Qu, Y., Roberts, J.D., Soares Fontes, A.P., Skov, K.A., Wu, P. and Zou, Y. (1995) Biochemistry 34, 15480-15486

23 Zaludová, R., Zakovská, A., Kaspárková, J., Balcarová, Z., Kleinwachter, V., Vrána, O., Farrell, N. and Brabec, V. (1997) Eur. J. Biochem. 246, 508-517

24 Batista de Carvalho, L.A.E., Lourenço, L.E. and Marques, M.P.M. (1999) J. Mol. Struct. 482-483, 639-646

25 Marques, M.P.M., Batista de Carvalho, L.A.E. and Tomkinson, J. (1999-2000) The Rutherford Appleton Laboratory, ISIS Facility Annual Report, CLRC

26 Marques, M.P.M. and Batista de Carvalho, L.A.E. (2000) in COST 917: Biogenically Active Amines in Food, vol, 4 (Morgan, D.M.L., White, A., Sánchez-Jiménez, F. and Bardocz, S., eds), p. 122, European Commission, Luxembourg

27 Marques, M.P.M., Batista de Carvalho, L.A.E. and Tomkinson, J. (2001-2002) The Rutherford Appleton Laboratory, ISIS Facility Annual Report, CLRC

28 Marques, M.P.M., Batista de Carvalho, L.A.E. and Tomkinson, J. (2002) J. Phys. Chem. A 106, 2473-2482

29 Amorim da Costa, A.M., Marques, M.P.M. and Batista de Carvalho, L.A.E. (2002) Vib. Spectrosc. 29, 61-67

30 Amorim da Costa, A.M., Marques, M.P.M. and Batista de Carvalho, L.A.E. (2003) J. Raman Spectrosc. 34, 357-366

31 Amorim da Costa, A.M., Batista de Carvalho, L.A.E. and Marques, M.P.M (2004) Vib. Spectrosc. 35, 165-171

32 Amado, A.M., Otero, J.C., Marques, M.P.M. and Batista de Carvalho, L.A.E. (2004) Chem. Phys. Chem. 5, 1837-1847

33 Batista de Carvalho, L.A.E., Marques, M.P.M. and Tomkinson, J. (2006) J. Phys. Chem. A 110, 12947-12954

34 Mirkin, N.G. and Krimm, S. (1993) J. Phys. Chem. 97, 13887-13895

35 Grillo, M.A. and Colombatto, S. (2004) Amino Acids 26, 3-8

36 Raasch, W., Schafer, U., Chun, J. and Dominiak, P. (2001) Вr. J. Pharm. 133, 755-780

37 Sener, A., Lebrun, F., Blaicher, F. and Malaisse, W.J. (1989) Biochem. Pharmacol. 38, 327-330

38 Satriano, J., Matsufuji, S., Murakami, Y., Lortie, M.J., Schwartz, D., Kelly, C.J., Hayashi, S.I. and Blantz, R.C. (1998) J. Biol. Chem. 273, 15313-15316

39 Dudkowska, M., Lai, J., Gardini, G., Stachurska, A., Grzelakowska-Sztabert, B., Colombatto, S. and Manteuffel-Cymborowska, M. (2003) Biochim. Biophys. Acta 1619, 159-166

40 Grundemann, D., Hahne, C., Berkels, R. and Schomig, E. (2003) J. Pharmacol. Exp. Ther. 304, 810-817 
41 Higashi, K., Yoshida, K., Nishimura, K., Momiyama, E., Kashiwagi, K.. Matsufuji, S., Shirahata, A. and Igarashi, K. (2004) J. Biochem. (Tokyo) 136, 533-539

42 Salvi, M., Battaglia, V., Mancon, M., Colombatto, S., Cravanzola, C., Calheiros, R., Marques, M.P.M., Grillo, M.A. and Toninello, A. (2006) Biochem. J. 396, 337-345

43 Toninello, A., Battaglia, V., Salvi, M., Calheiros, R. and Marques, M.P.M. (2006) Struct. Chem. 17, 163-175

44 Marques, M.P.M., Batista de Carvalho, L.A.E. and Tomkinson, J. (2003) The Rutherford Appleton Laboratory, ISIS Facility Annual Report, CLRC
45 Marques, M.P.M., Girão da Cruz, M.T., Pedroso de Lima, M.C., Gameiro, A., Pereira, E. and Garcia, P. (2002) Biochim. Biophys. Acta 1589, 63-70 46 Teixeira, L.J., Seabra, M., Reis, E., Girão da Cruz, M.T., Pedroso de Lima, M.C., Регеira, E., Miranda, M.A. and Marques, M.P.M. (2004) J. Med. Chem. 47, 2917-2925

47 Fiuza, S.M., Amado, A.M., Oliveira, P.J., Sardão, V.A., Batista de Carvalho, L.A.E. and Marques, M.P.M. (2006) Lett. Drug Des. Dev. 3, 149-151

Received 13 October 2006 